$\angle$ Research Square

\title{
Sleep and Its Importance for Health-Related Quality of Life in 3-10-Year-Old Children
}

\section{Anna Lena Sundell}

Odontologiska Institutionen i Jonkoping

Charlotte Angelhoff ( $\square$ charlotte.angelhoff@liu.se)

Linkopings universitet https://orcid.org/0000-0002-0174-8630

\section{Research article}

Keywords: Child, Child Preschool, Family, Primary Health Care, Sleep, Quality of Life

Posted Date: August 28th, 2020

DOI: https://doi.org/10.21203/rs.3.rs-60059/v1

License: (9) (1) This work is licensed under a Creative Commons Attribution 4.0 International License. Read Full License 


\section{Abstract}

Background: Considering the reports of increasing sleep problems in children, affecting health and well-being in young children and their families, we found it important to gain more knowledge about sleep and its correlation to health-related quality of life (HRQoL) in young, healthy children. The aim with this study was to describe sleep quality, sleep duration, and HRQoL in healthy 3-10-year-old children and to test associations between children's sleep and HRQoL.

Methods: Parents of 160 children (average age: 6.9 years, SD \pm 2.2 ) participated in the study. Sleep onset problems (SOP), sleep maintenance problems (SMP), and sleep duration were measured by the Pediatric Insomnia Severity Index (PISI). KIDSCREEN-27 was used to measure HRQoL in five dimensions: physical wellbeing, psychological well-being, autonomy and parent relation, social support and peers, and school environment.

Results: The average score was 2.2 for SOP (SD +/-2.2) and 1.3 for SMP (SD +/-1.6). Almost all children (98\%) slept between 8 and 13 hours per night. Younger children had statistically significantly more sleep problems than older children. Correlations were found between SOP and poor psychological well-being $(p<0.05, \rho=-$ $0.16)$, and between SMP and poor psychological well-being $(p<0.05, \rho=-0.21)$, poor school environment $(p<$ $0.01, \rho=-0.29)$, and poor social support and peers $(p<0.05, \rho=-0.19)$.

Conclusion: Children's sleep associates with psychosocial well-being, school functioning and relations to peers, and need to be acknowledged in child health care settings and schools.

\section{Background}

Adequate sleep duration, good sleep quality, regularity, and the absence of sleep disruptions are important factors for healthy sleep in children [1, 2]. Adolescents have recently described good sleep in terms of sleep duration, bedtime routines, short sleep onset latency, absence of nocturnal awakenings, and waking up feeling rested and joyful [3], which is in line with the definition of sleep quality described by Ohayon et al. [4]. According to the Consensus Statement of the American Academy of Sleep Medicine, pre-school children (35 years old) need 10 to 13 hours of sleep and school-aged children (6-10 years old) need 9 to 12 hours of sleep on a regular basis to maintain optimal health [2].

Recently, studies have reported increasing sleep problems in children and adolescents [5-7], leading to physical, psychological, and cognitive problems $[6,8,9]$. Sleep problems influence emotion generation and regulation of neurobiological behavioral and cognitive processes, mainly through behavioral tendencies and neurological changes. Consequently, insufficient sleep impacts emotional reactivity, leading to more negative and less positive emotions [10,11], but also to impaired executive functions, which negatively affects learning abilities and school performance $[9,12]$. Yet, a lack of education and experience is a challenge for pediatric health care providers, who may avoid asking about the child's sleep because they do not know how to respond if there is a sleep issue [13].

Further, sleep is associated with health-related quality of life (HRQoL). Yet, there is a lack in the literature of these associations in young children. A recently published study of 9-11-year-old children in 12 countries 
reveals that self-reported poor sleep in children is associated with HRQoL, but it found no associations between device-based measured sleep and HRQoL [14]. Magee et al. [15] report in an Australian cohort study that disordered sleep and minor sleep disturbance in 10- and 11-year-old children relate to poorer HRQoL, which worsen over time. Price et al. [16] report weak and inconsistent correlations between sleep duration and HRQoL in 4-9-year-old children, suggesting that parameters other than sleep duration could be more meaningful to understand optimal sleep in children.

According to the World Health Organization [17], HRQoL is the personal judgment of one's health and diseases, including a multidimensional assessment of a person's satisfaction with life and the perceptions of his or her position in life in different contexts. Previous studies of children's sleep or HRQoL have mostly focused on different health problems and diagnoses, and no study is found of sleep and HRQoL in young healthy children. Considering the reports of increasing sleep problems in healthy children, affecting health and well-being in young children and their families, we found it important to gain more knowledge about sleep and its correlation to HRQoL in a healthy population of young children, using validated instruments. The aim of the current study was to describe sleep quality, sleep duration, and HRQoL in healthy 3-10-year-old children and to test associations between children's sleep and HRQoL.

\section{Methods}

\section{Design}

This is an explorative and descriptive study with a cross-sectional design. The study was approved by the Regional Ethics Committee for Medical Research (Dnr 2018/175-31) in accordance with the Helsinki declaration [18].

\section{Participants and procedure}

A consecutive sample of Swedish-speaking parents of children between 3 and 11 years old with no major health problems were asked to participate when visiting child health care centers in Region Östergötland and public dental services in Region Jönköpings län for a regular health check-up with their child. It is not known how many parents the staff excluded due to language difficulties or health problems or how many parents declined to participate. After providing informed consent, the parents answered the Pediatric Insomnia Severity Index (PISI) and KIDSCREEN-27 proxy version for their children. In cases where the parent had more than one child between 3 and 11 years old, they were asked to fill out the questionnaires for the siblings as well. The coded, completed forms were placed in a postage-paid envelope and returned to the authors. Data were collected between September 2018 and January 2019.

\section{Measurements}

Sleep was estimated by the six-item Swedish version of the PISI, a parent-proxy questionnaire for children between 3 and 10 years old. The items follow the ICSD-II general criteria for insomnia, including difficulties falling asleep, difficulties maintaining sleep, and daytime impairment. Five of the items are scored on a sixpoint Likert-type scale ( 0 = never, 5 = always), and total hours of sleep on most nights are rated on a six-point scale $(0=11-13$ hours, $5=$ less than 5 hours). Higher values indicate more sleep problems. The questionnaire 
refers to the children's sleep over the last week and consists of two dimensions of sleep difficulties: sleep onset problems (SOP) and sleep maintenance problems (SMP). PISI is validity and reliability tested with good results for brief screening of insomnia $[19,20]$. The construct reliability was good in this sample (Cronbach's a 0.86 for SOP and 0.62 for SMP).

The Swedish proxy version of KIDSCREEN-27 was used to explore HRQoL. KIDSCREEN-27 was developed in an intercountry collaboration network including 13 European countries; created after literature reviews, consultations with experts, and discussions in focus groups with children; and thereafter tested. The 27 items are scored on a five-point Likert-type scale ( $1=$ no agreement at all, $5=$ total agreement). The generic questionnaire includes five dimensions of HRQoL: physical well-being (level of physical activity, energy, and fitness), psychological well-being (positive emotions and satisfaction with life), autonomy and parent relation (perceived level of autonomy, interaction between child and parent, and feeling loved and supported), social support and peers (interaction between child and peers), and school environment (perception of cognitive capacity, learning, concentration, and feelings about school). The questions refer to the children's HRQoL over the last week. Higher values indicate better HRQoL, and T-scores of 50 and SD \pm 10 are regarded as normal. The measurement has acceptable reliability (Pearson's r $0.61-0.74$ ) and validity, as well as internal consistency (Cronbach's a 0.79-0.84), in analyses including several European languages [21,22]. In this sample, Cronbach's a was 0.94 . Permission to utilize the Swedish version of KIDSCREEN-27 was granted by the copyright holder.

\section{Statistical analysis}

Rasch measurement analysis was used for all five KIDSCREEN-27-dimensions and thereafter transformed to Tvalues, according to the manual. Descriptive statistics are presented as means $(\mathrm{m})$, standard deviations (SD), frequencies $(n)$, and percentage (\%). Nonparametric tests were used, as both the PISI and KIDSCREEN-27 include qualitative variables. The Mann-Whitney U-test was performed to calculate differences between genders. Spearman's rho ( $\rho$ ) was used for comparison of dimensions of HRQoL and dimensions of sleep problems, gender, and age. A two-samples t-test was conducted to compare KIDSCREEN-27 between our sample and the European reference population [21]. All reported $p$-values were two-sided, and a $p$-value of $<0.05$ was considered statistically significant. Data were processed using IBM SPSS statistics version 25 .

\section{Results}

Parents of 188 children gave consent to participate in the study, of whom $18(15 \%)$ were excluded due to incorrectly filled out questionnaires. The final sample consisted of 160 children at an average age of 6.9 years old ( $S D \pm 2.2$, age range 3.0 to 10.7 years), of whom $44 \%$ were girls.

Mean values on sleep outcomes are presented in Table 1. Fourteen children (9\%) had trouble falling asleep at bedtime, and 25 children (16\%) took longer than 30 minutes to fall asleep. Girls were reported to have significantly more problems falling asleep ( $\mathrm{m} 2.67, \mathrm{SD} \pm 2.3, p=0.01$ ) than boys ( $\mathrm{m} 1.9, \mathrm{SD} \pm 2.0$ ). Eight children $(5 \%)$ woke more than once during the night, two children had trouble returning to sleep after waking, and one child appeared sleepy during the day. Almost all children $(n=156,98 \%)$ slept between 8 and 13 hours per night. 
Table 1

Description of the children's sleep and health-related quality of life, and differences

between girls and boys

\begin{tabular}{|c|c|c|c|c|}
\hline & $\begin{array}{l}\text { All children } \\
n=160 \\
\text { mean (SD) }\end{array}$ & $\begin{array}{l}\text { Girls } \\
n=70 \\
\text { mean (SD) }\end{array}$ & $\begin{array}{l}\text { Boys } \\
n=90 \\
\text { mean (SD) }\end{array}$ & $p$-value ${ }^{a}$ \\
\hline Age & $6.9(2.2)$ & $7.0(2.1)$ & $6.9(2.3)$ & .17 \\
\hline \multicolumn{5}{|l|}{ PISI } \\
\hline Sleep onset problems & $2.2(2.2)$ & $2.7(2.3)$ & $1.9(2.0)$ & $.01 *$ \\
\hline Sleep maintenance problems & $1.3(1.6)$ & $1.3(1.5)$ & $1.3(1.7)$ & .99 \\
\hline Total hours of sleep ${ }^{b}$ & $1.0(0.6)$ & $1.1(0.7)$ & $0.9(0.5)$ & .06 \\
\hline \multicolumn{5}{|l|}{ KIDSCREEN } \\
\hline Physical well-being & $54.6(8.5)$ & $54.0(8.9)$ & $55.1(8.3)$ & .77 \\
\hline Psychological well-being & $55.2(9.5)$ & $54.8(9.5)$ & $55.5(9.6)$ & .59 \\
\hline Autonomy and parent relation & $56.3(9.2)$ & $56.7(10.2)$ & $55.9(8.4)$ & .26 \\
\hline Social support and peers & $55.4(8.0)$ & 54.7 (7.9) & $56.0(8.0)$ & .95 \\
\hline School & $58.1(9.1)$ & $59.6(8.2)$ & $56.9(9.6)$ & .08 \\
\hline \multicolumn{5}{|l|}{ a Mann-Whitney U-test. } \\
\hline \multicolumn{5}{|c|}{ b Six-point Likert-scale from $0=11-13$ hours to $5=$ less than 5 hours. } \\
\hline * significant at $p<.05$ & & & & \\
\hline
\end{tabular}

A statistically significant correlation was found between SOP and total hours of sleep $(p=0.03, \rho=0.17)-$ i.e., the more problems falling asleep, the fewer hours of sleep. Moreover, the child's age correlated significantly with SOP $(p=0.03, \rho=-0.17)$ and SMP $(p=0.02, \rho=-0.18)$, indicating that the lower the age, the more sleep problems. When dichotomizing the children's ages into two groups - pre-school (3-5 years) and school-aged (6-10 years) children - there was a statistically significant correlation in SOP $(p=0.02, \rho=-0.19)$, but not in SMP. There was also a statistically significant correlation between the child's age and total hours of sleep ( $p=$ $0.03, \rho=0.18)$, suggesting that sleep duration decreases with the child's age. This correlation remained significant when we compared the dichotomized groups of pre-school and school-aged children $(p=0.03, \rho=$ $0.17)$.

Scores for the five dimensions of KIDSCREEN-27 are presented in Table 1. Nearly all children $(n=155,97 \%)$ reported good, very good, or excellent general health. Three children had poor or fairly poor general health (item no. 1). There was a significant difference in the scores for the children in our study $(\mathrm{m} 56, \mathrm{SD} \pm 7)$ and the European reference population ( $\mathrm{m} \mathrm{50}, \mathrm{SD} \pm 10, t[179]=-10.6, p<0.01)$, indicating that the children in our study had higher HRQoL than the average population. 
SOP was significantly correlated with poor psychological well-being $(p<0.05, \rho=-0.16)$, and SMP was significantly correlated with poor psychological well-being $(p<0.05, \rho=-0.21)$, poor school environment $(p<$ $0.01, \rho=-0.29)$, and poor social support and peers $(p<0.05, \rho=-0.19)$ (Table 2$)$. Age and gender were not statistically significantly associated to HRQoL.

Table 2

Correlations between sleep and health-related quality of life $\mathrm{e}^{\mathrm{a}}(n=160)$

\begin{tabular}{|c|c|c|c|c|c|c|}
\hline & $\begin{array}{l}\text { Sleep } \\
\text { onset } \\
\text { problemsp }\end{array}$ & $\begin{array}{l}\text { Sleep } \\
\text { maintenance } \\
\text { problems } \rho\end{array}$ & $\begin{array}{l}\text { Physical } \\
\text { well- } \\
\text { being }\end{array}$ & $\begin{array}{l}\text { Psychological } \\
\text { well-beingp }\end{array}$ & $\begin{array}{l}\text { Autonomy } \\
\text { and parent } \\
\text { relationp }\end{array}$ & $\begin{array}{l}\text { Social } \\
\text { support } \\
\text { and } \\
\text { peers } \rho\end{array}$ \\
\hline $\begin{array}{l}\text { Sleep } \\
\text { maintenance } \\
\text { problems }\end{array}$ & $0.242^{\star \star}$ & & & & & \\
\hline $\begin{array}{l}\text { Physical well- } \\
\text { being }\end{array}$ & -0.059 & $-0.159^{\star}$ & & & & \\
\hline $\begin{array}{l}\text { Psychological } \\
\text { well-being }\end{array}$ & $-0.163^{*}$ & $-0.206^{\star \star}$ & $0.553^{\star \star \star}$ & & & \\
\hline $\begin{array}{l}\text { Autonomy } \\
\text { and parent } \\
\text { relation }\end{array}$ & -0.072 & $-0.163^{*}$ & $0.536^{\star \star \star}$ & $0.528^{\star \star \star}$ & & \\
\hline $\begin{array}{l}\text { Social } \\
\text { support and } \\
\text { peers }\end{array}$ & -0.112 & $-0.186^{*}$ & $0.375^{\star \star \star}$ & $0.362^{\star \star \star}$ & $0.385^{\star \star \star}$ & \\
\hline $\begin{array}{l}\text { School } \\
\text { environment }\end{array}$ & -0.124 & $-0.286^{\star \star \star}$ & $0.478^{\star \star \star}$ & $0.538^{\star \star \star}$ & $0.505^{\star \star \star}$ & $0.448^{\star \star \star}$ \\
\hline
\end{tabular}

a Spearman's rho $(\rho)$.

* Correlation is significant at the 0.05 level (two-tailed).

${ }^{* \star}$ Correlation is significant at the 0.01 level (two-tailed).

${ }^{\star \star \star}$ Correlation is significant at the 0.001 level (two-tailed).

\section{Discussion}

The main results of this study were the correlations between sleep and the HRQoL-dimensions psychological well-being, school environment, and social support and peers. It is difficult to say what comes first, sleep disturbances or poor health-related quality of life. Certainly, they are associated with each other and likely connected with each other like a vicious circle. Sleep disturbances in children have previously been reported to be associated with emotional problems such as anxiety [23], leading to late bedtimes, poor sleep duration, and frequent night awakenings [24, 25]. In a systematic review, longer sleep duration has been found to be related with better emotional regulation and quality of life in 5-17-year-old children [26]. The overall sleep duration for the children in the present study was 9-11 hours per night, which is in line with general sleep duration recommendations $[2,27]$, but contrasts with other studies describing less sleep duration in the latest 
decennium $[7,28]$. Longer sleep duration was seen in younger children compared to older. Biological rhythm of sleep and waking is regulated through both circadian and homeostatic processes, but also active and complex neurophysiologic processes that change over the life course, especially in the first five years, leading to longer sleep duration [6]. Furthermore, it could be expected that older children have later bed times than younger children. According to Norell-Clarke and Hagquist [7], there has been a change in bedtime over time, with later bedtimes, less sleep, and sleep onset difficulties in 11-year-old children in Sweden. However, the children in our study were below the age of 11 years and cannot be fairly compared to the above-mentioned study. The widespread possible answer (3 hours) in the PISI (item no. 6: total hours of sleep on most nights) should also be taken into consideration. The PISI may be more appropriate for screening sleep problems than measuring subjective sleep duration.

In present study, problems maintaining sleep were related to cognitive capacity and feelings about school, as well as the social relation with peers and friends. These results are in line with those reported by Gustafsson et al. [29], who report associations between daytime sleepiness and HRQoL, including school-related sub-score measured by the Pediatric Quality of Life Inventory, in 10-15-year-old Finnish school children. Several other studies have revealed the association between sleep and impaired school performance, academic achievement, attention, and learning motivation [30, 31]. Furthermore, peer victimization, including bullying, has been shown to be related to sleep problems [32-34]. The relation between peer victimization and sleep problems is stronger in younger than older children [32]. Being bullied is associated with symptoms of severe mental health problems and can have serious consequences over time $[35,36]$. Direct questions about victimization or bullying are not included in KIDSCREEN-27, but the quality of the interaction between the child and peers as well as their perceived support are explored. Low scores are interpreted as feeling excluded and not accepted by peers [21]. Knowing that sleep is important to manage school as well as being able to interact with peers and friends, teachers, and school nurses should inquire about both the quality and quantity of the child's sleep on a routine basis to promote health and well-being in school children, and advice and support should be offered to the children and their parents in following good sleep hygiene principles.

In the present study, only one child out of 10 was reported to have trouble falling asleep at night, and one out of six took longer than 30 minutes to fall asleep. Moreover, we found that the child's age was associated with sleep problems; the lower the age, the more problems. It has been previously explained that sleep problems, such as nightmares, sleep terrors, and sleep walking, are more common in pre-schoolers compared to schoolaged children [37, 38]. It is important to acknowledge children's sleep as well as psychological well-being when meeting the child at regular health visits. Advice about calming bed routines and healthy sleep habits in combination with good sleep hygiene should be provided early to parents to help prevent sleep problems and manage sleep problems when they happen [6].

This study is one of few studies exploring healthy children's sleep and its correlation to HRQoL. The study has several strengths, such as a representative sample, even distribution between girls and boys, and validated measurements, and it provides valuable insight into the importance of sleep for psychological well-being, school, and social relations. However, there are some limitations that need to be mentioned. Since we used parent-proxy reports, our findings must be interpreted with caution. Sleep problems could have been underreported because of parents' unawareness of their child's behaviors at night, especially older children. Children's self-reports have been shown to reveal more sleep disturbances compared to parents' reports [39, 
40]. Moreover, only Swedish-speaking parents were included in the study, which excludes a large part of the population. Another limitation is that the PISI does not have a cut-off for acknowledging symptoms of severe sleep problems. Future research should focus on determining a cut-off score, as presented in the adult version of the Insomnia Severity Index [41]. Furthermore, the validity of subjective measurements is always questionable. A validation of the PISI to an objective assessment tool, such as actigraphy or polysomnography, would be of highest interest.

\section{Conclusion}

Children in the present study had few sleep problems and better HRQoL compared to a reference population. We could also reveal that psychosocial well-being, school functioning, lower social support, and relations to peers depended on the child's sleep. This study highlights the importance of acknowledging children's sleep in child health care settings and schools. Moreover, our findings can improve health care professionals' awareness of the importance of the impact of children's sleep on their HRQoL.

\section{List Of Abbreviations}

HRQoL Health-related quality of life

PISI The Pediatric Insomnia Severity Index

SMP Sleep maintenance problems

SOP Sleep onset problems

\section{Declarations}

Ethics approval and Consent to Participate: This study was performed in line with the principles of the Declaration of Helsinki. Informed written consent was obtained from all participants. Approval was granted by the Regional Ethics Committee for Medical Research (Dnr 2018/175-31).

Consent for publication: Not applicable

Availability of data and material: The datasets used and analyzed during the current study are available from the corresponding author on reasonable request.

Competing interests: The authors declare that they have no competing interests.

Funding: This study received funding from the Futurum Academy of Health and Care, Jönköping County Council, and Forsknings-och stipendieförvaltningen i Östergötland 2018 (Stiftelseförvaltningen - US stiftelse för medicinsk forskning: Barndiabetesforskning [92011]; Hälsofonden, Medicinska fakultetens fondstyrelse).

Author' contributions: Both authors contributed equally to this work. Both authors have read and approved the manuscript 
Acknowledgements: The authors want to thank the parents for answering the questionnaires; the staff at Barnhälsovården, Capio Vårdcentral Berga, Folktandvården Hälsan, Mullsjö, Norrahammar, Sävsjö, and Tranås for help with data collection; professors Peter Johansson and Erland Svensson for their support during study design and data collection; and professor Gudrún Kristjánsdóttir for critical revision of the manuscript. Special thanks go to Lucja Stankowska Malko for the kind help with data administration.

\section{References}

1. Lewin, D. S., Wolfson, A. R., Bixler, E. O., \& Carskadon, M. A. (2016). Duration Isn't Everything. Healthy Sleep in Children and Teens: Duration, Individual Need and Timing. J Clin Sleep Med, 12(11), 1439-1441, doi:10.5664/jcsm.6260.

2. Paruthi, S., Brooks, L. J., D'Ambrosio, C., Hall, W. A., Kotagal, S., Lloyd, R. M., et al. (2016). Recommended Amount of Sleep for Pediatric Populations: A Consensus Statement of the American Academy of Sleep Medicine. J Clin Sleep Med, 12(6), 785-786, doi:10.5664/jcsm.5866.

3. Lundgren, J., Norell-Clarke, A., Hellström, I., \& Angelhoff, C. (2020). Adolescents' Experiences of Staying Overnight at Family-Centered Pediatric Wards. SAGE Open Nursing, 6, 2377960819900690, doi:10.1177/2377960819900690.

4. Ohayon, M., Wickwire, E. M., Hirshkowitz, M., Albert, S. M., Avidan, A., Daly, F. J., et al. (2017). National Sleep Foundation's sleep quality recommendations: first report. Sleep Health, 3(1), 6-19, doi:10.1016/j.sleh.2016.11.006.

5. Chaput, J. P., Gray, C. E., Poitras, V. J., Carson, V., Gruber, R., Birken, C. S., et al. (2017). Systematic review of the relationships between sleep duration and health indicators in the early years (0-4 years). BMC Public Health, 17(Suppl 5), 855, doi:10.1186/s12889-017-4850-2.

6. Bathory, E., \& Tomopoulos, S. (2017). Sleep Regulation, Physiology and Development, Sleep Duration and Patterns, and Sleep Hygiene in Infants, Toddlers, and Preschool-Age Children. Curr Probl Pediatr Adolesc Health Care, 47(2), 29-42, doi:10.1016/j.cppeds.2016.12.001.

7. Norell-Clarke, A., \& Hagquist, C. (2017). Changes in sleep habits between 1985 and 2013 among children and adolescents in Sweden. Scand J Public Health, 1403494817732269, doi:10.1177/1403494817732269.

8. Matricciani, L., Paquet, C., Galland, B., Short, M., \& Olds, T. (2019). Children's sleep and health: A metareview. Sleep Med Rev, 46, 136-150, doi:10.1016/j.smrv.2019.04.011.

9. Medic, G., Wille, M., \& Hemels, M. E. (2017). Short- and long-term health consequences of sleep disruption. Nat Sci Sleep, 9, 151-161, doi:10.2147/nss.s134864.

10. Palmer, C. A., \& Alfano, C. A. (2017). Sleep and emotion regulation: An organizing, integrative review. Sleep Med Rev, 31, 6-16, doi:10.1016/j.smrv.2015.12.006.

11. Tempesta, D., Socci, V., De Gennaro, L., \& Ferrara, M. (2018). Sleep and emotional processing. Sleep Med Rev, 40, 183-195, doi:10.1016/j.smrv.2017.12.005.

12. Owens, J. A., \& Weiss, M. R. (2017). Insufficient sleep in adolescents: causes and consequences. Minerva Pediatr, 69(4), 326-336, doi:10.23736/s0026-4946.17.04914-3. 
13. Honaker, S. M., \& Meltzer, L. J. (2016). Sleep in pediatric primary care: A review of the literature. Sleep Med Rev, 25, 31-39, doi:10.1016/j.smrv.2015.01.004.

14. Xiao, Q., Chaput, J. P., Olds, T., Fogelholm, M., Hu, G., Lambert, E. V., et al. (2020). Sleep characteristics and health-related quality of life in 9- to 11-year-old children from 12 countries. Sleep Health, 6(1), 4-14, doi:10.1016/j.sleh.2019.09.006.

15. Magee, C. A., Robinson, L., \& Keane, C. (2017). Sleep quality subtypes predict health-related quality of life in children. Sleep Med, 35, 67-73, doi:10.1016/j.sleep.2017.04.007.

16. Price, A. M. H., Quach, J., Wake, M., Bittman, M., \& Hiscock, H. (2016). Cross-sectional sleep thresholds for optimal health and well-being in Australian 4-9-year-olds. Sleep Med, 22, 83-90, doi:10.1016/j.sleep.2015.08.013.

17. The World Health Organization Quality of Life assessment (WHOQOL): position paper from the World Health Organization (1995). Soc Sci Med, 41(10), 1403-1409, doi:10.1016/0277-9536(95)00112-k.

18. World Medical Association (2002). World Medical Association Declaration of Helsinki. Ethical principles for medical research involving human subjects. Nursing ethics, 9(1), 105-109.

19. Byars, K. C., Simon, S. L., Peugh, J., \& Beebe, D. W. (2017). Validation of a Brief Insomnia Severity Measure in Youth Clinically Referred for Sleep Evaluation. J Pediatr Psychol, 42(4), 466-475, doi:10.1093/jpepsy/jsw077.

20. Angelhoff, C., Johansson, P., Svensson, E., \& Sundell, A. L. (2019). Swedish Translation and Validation of the Pediatric Insomnia Severity Index. 1 December 2019, PREPRINT (Version 1) available at Research Square https://dx.doi.org/10.21203/rs.2.17825/v1

21. Ravens-Sieberer, U., Gosch, A., Erhart, M., Auquier, P., von Rueden , U., Nickel, J., et al. (2006). The KIDSCREEN questionnaires. Quality of life questionnaire for children and adolescents. Handbook. Lengerich: Pabst science.

22. Ravens-Sieberer, U., Herdman, M., Devine, J., Otto, C., Bullinger, M., Rose, M., et al. (2014). The European KIDSCREEN approach to measure quality of life and well-being in children: development, current application, and future advances. Qual Life Res, 23(3), 791-803, doi:10.1007/s11136-013-0428-3.

23. Gregory, A. M., \& Sadeh, A. (2012). Sleep, emotional and behavioral difficulties in children and adolescents. Sleep Med Rev, 16(2), 129-136, doi:10.1016/j.smrv.2011.03.007.

24. Hudson, J. L., Gradisar, M., Gamble, A., Schniering, C. A., \& Rebelo, I. (2009). The sleep patterns and problems of clinically anxious children. Behav Res Ther, 47(4), 339-344, doi:10.1016/j.brat.2009.01.006.

25. Forbes, E. E., Bertocci, M. A., Gregory, A. M., Ryan, N. D., Axelson, D. A., Birmaher, B., et al. (2008). Objective sleep in pediatric anxiety disorders and major depressive disorder. J Am Acad Child Adolesc Psychiatry, 47(2), 148-155, doi:10.1097/chi.0b013e31815cd9bc.

26. Chaput, J. P., Gray, C. E., Poitras, V. J., Carson, V., Gruber, R., Olds, T., et al. (2016). Systematic review of the relationships between sleep duration and health indicators in school-aged children and youth. Appl Physiol Nutr Metab, 41(6 Suppl 3), S266-282, doi:10.1139/apnm-2015-0627.

27. Chaput, J. P., Dutil, C., \& Sampasa-Kanyinga, H. (2018). Sleeping hours: what is the ideal number and how does age impact this? Nat Sci Sleep, 10, 421-430, doi:10.2147/NSS.S163071.

28. Ophoff, D., Slaats, M. A., Boudewyns, A., Glazemakers, I., Van Hoorenbeeck, K., \& Verhulst, S. L. (2018). Sleep disorders during childhood: a practical review. Eur J Pediatr, 177(5), 641-648, doi:10.1007/s00431- 
018-3116-z.

29. Gustafsson, M. L., Laaksonen, C., Aromaa, M., Asanti, R., Heinonen, O. J., Koski, P., et al. (2016). Association between amount of sleep, daytime sleepiness and health-related quality of life in schoolchildren. J Adv Nurs, 72(6), 1263-1272, doi:10.1111/jan.12911.

30. Li, S., Arguelles, L., Jiang, F., Chen, W., Jin, X., Yan, C., et al. (2013). Sleep, school performance, and a school-based intervention among school-aged children: a sleep series study in China. PLoS One, 8(7), e67928, doi:10.1371/journal.pone.0067928.

31. Gruber, R., Somerville, G., Enros, P., Paquin, S., Kestler, M., \& Gillies-Poitras, E. (2014). Sleep efficiency (but not sleep duration) of healthy school-age children is associated with grades in math and languages. Sleep Med, 15(12), 1517-1525, doi:10.1016/j.sleep.2014.08.009.

32. van Geel, M., Goemans, A., \& Vedder, P. H. (2016). The relation between peer victimization and sleeping problems: A meta-analysis. Sleep Med Rev, 27, 89-95, doi:10.1016/j.smrv.2015.05.004.

33. Zhou, Y., Guo, L., Lu, C. Y., Deng, J. X., He, Y., Huang, J. H., et al. (2015). Bullying as a risk for poor sleep quality among high school students in China. PLoS One, 10(3), e0121602, doi:10.1371/journal.pone.0121602.

34. Donoghue, C., \& Meltzer, L. J. (2018). Sleep it off: Bullying and sleep disturbances in adolescents. J Adolesc, 68, 87-93, doi:10.1016/j.adolescence.2018.07.012.

35. Arseneault, L., Bowes, L., \& Shakoor, S. (2010). Bullying victimization in youths and mental health problems: 'much ado about nothing'? Psychol Med, 40(5), 717-729, doi:10.1017/s0033291709991383.

36. Bjereld, Y., Daneback, K., Gunnarsdottir, H., \& Petzold, M. (2015). Mental health problems and social resource factors among bullied children in the Nordic countries: a population based cross-sectional study. Child Psychiatry Hum Dev, 46(2), 281-288, doi:10.1007/s10578-014-0468-0.

37. Mindell, J. A., \& Owens, J. A. (2015). A clinical guide to pediatric sleep: diagnosis and management of sleep problems. Philadelphia: Lippincott Williams \& Wilkins.

38. Davis, K. F., Parker, K. P., \& Montgomery, G. L. (2004). Sleep in infants and young children: Part two: common sleep problems. Journal of Pediatric Health Care, 18(3), 130-137, doi:https://doi.org/10.1016/S0891-5245(03)00150-0.

39. Owens, J. A., Spirito, A., McGuinn, M., \& Nobile, C. (2000). Sleep habits and sleep disturbance in elementary school-aged children. J Dev Behav Pediatr, 27(1), 27-36.

40. Gregory, A. M., Rijsdijk, F. V., \& Eley, T. C. (2006). A twin-study of sleep difficulties in school-aged children. Child Dev, 77(6), 1668-1679, doi:10.1111/j.1467-8624.2006.00966.x.

41. Bastien, C. H., Vallieres, A., \& Morin, C. M. (2001). Validation of the Insomnia Severity Index as an outcome measure for insomnia research. Sleep Med, 2(4), 297-307, doi:10.1016/s1389-9457(00)00065-4. 